\title{
The effect of nutritional treatment on immune function
}

\section{Wpływ leczenia żywieniowego na funkcjonowanie układu immunologicznego}

\author{
Juliusz Kosel, Urszula Kościuczuk, Andrzej Siemiątkowski \\ Department of Anaesthesiology and Intensive Care, Medical University of Bialystok, Poland
}

Prz Gastroenterol 2013; 8 (3): 147-155

DOI: $10.5114 /$ pg.2013.36327

Key words: immunonutrition, acute pancreatitis, perioperative therapy, sepsis.

Słowa kluczowe: immunożywienie, ostre zapalenie trzustki, terapia okołooperacyjna, sepsa.

Address for correspondence: Juliusz Kosel MD, Department of Anaesthesiology and Intensive Care, Medical University of Bialystok, 24 A M. Skłodowskiej-Curie St, 15-276 Bialystok, Poland, phone: +48 8574683 02, e-mail: jkosel@umwb.edu.pl

\begin{abstract}
This article reviews the role of immunoactive components of nutrition. The evidence for indications, limitations and possibilities of providing an immunonutritional regimen is supported by the latest guidelines of the Society of Critical Care Medicine (SCCM) and the American Society for Parenteral and Enteral Nutrition (A.S.P.E.N.). The article presents the role of immunonutrition in therapy of acute pancreatitis, in the perioperative period and in sepsis now and its possibilities in the future.
\end{abstract}

\section{Introduction}

Implementation of the appropriate form of nutrition is an important aspect of therapy in the intensive care unit. Providing essential nutrients, vitamins, micro- and macroelements with the proper balance of quantity and quality is an important part of complex treatment. Nutritional status and nutrient resources contribute to the maintenance of internal homeostasis [1, 2].

The main nutrients are: proteins, carbohydrates, lipids, trace elements and vitamins. According to the route of providing the mixture of nutrients the therapy may be divided into: oral nutrition, enteral nutrition (consisting of the delivery of nutrients to the gastrointestinal tract with a gastric, duodenal or enteral tube) and parenteral nutrition (delivering nutrient factors through peripheral or central vascular vessels). Feeding through the gastrointestinal tract is considered to be more physiological and advantageous than parenteral nutrition $[3,4]$. The choice of the appropriate method depends on

\section{Streszczenie}

W pracy omówiono znaczenie składników pokarmowych o dziataniu immunomodulującym. Wskazania do stosowania immunoterapii żywieniowej przedstawiono na podstawie wytycznych American Society for Parenteral and Enteral Nutrition (A.S.P.E.N.) oraz Society of Critical Care Medicine (SCCM). W artykule zwrócono szczególną uwagę na obiecujący rozwój i zastosowania tej metody żywienia. Ponadto przedstawiono znaczenie immunoterapii żywieniowej w leczeniu ostrego zapalenia trzustki, $u$ chorych $w$ okresie okołooperacyjnym, w terapii choroby nowotworowej i sepsy.

disease severity, expected duration of nutrition therapy and prognosis. The gastrointestinal tube should be used for up to 4 weeks, and in patients requiring long-term nutritional therapy surgical approaches - gastrostomy or jejunostomy - are preferable $[3,5]$.

The main objective of nutrition, regardless of its type, is to provide essential nutrients. The second objective, in respect of seriously ill patients, is the creation of a metabolic and immunological response facilitating recovery. This second aspect results from clinical studies, according to which certain nutrients showed an immunomodulating effect [6]. Development of research on the effects of nutrients on immune status and function of the immune system in humans occurred in the second half of the twentieth century, when Scrimshaw. published in the World Health Organization's first document of this issue. Since that time, scientists and clinicians have been looking for an explanation of many phenomena and examining the mechanisms of influence of diet on components of the immune system [7]. 
The modification of feeding ensuring increased supply of nutrients amplifying effects of particular components of the immune system is referred to as immunonutrition. Taking into account the chemical and exogenous origin of nutrients, immunonutrition is sometimes also called pharmaconutrition $[3,8]$. Grimble defined immunonutrition as modulation of the activity of the immune system or the effects of activation of the immune system by specific nutrients or food components given in excess of the normal amount in the diet [1].

The nutrients with confirmed regulatory effects on the immune system are: saturated amino acids (arginine), unsaturated amino acids (glutamine, glycine), sulfur amino acids, nucleotides, polyunsaturated fatty acids $(\omega-3, \omega-6)$, antioxidants (vitamin C, vitamin E, $\beta$-carotene) and trace elements (selenium, copper, zinc, iron) $[1-3,9,10]$

\section{Expressions of traumatic stress}

In the 1940s, David Cuthberson (Check correct name) described multidirectional changes that occur in the body due to injury. Indeed, injury can be understood not only in the mechanical sense, but also as a factor (biological - infection) or disorder (hypoxia, ischemia, inflammatory process) which represents the risk/homeostasis disturbance requiring intensive therapy. These factors trigger a series of changes resulting from the creation of systemic threat and induction of a defense reaction of the body. Cytokines and other inflammatory mediators, afferent transmission from pain receptors, proprioceptors, and baroreceptors pose an effect of hypothalamic stimulation, where many other factors and hormones are secreted (growth hormone releasing factor - GHRF, corticotropin releasing factor - CRF), which stimulates the pituitary gland to increased secretion of adrenocorticotropic hormone (ACTH) and growth hormone $(\mathrm{GH})$. The metabolic state of the body is mainly affected by the hormonal stimulation. Increased secretion of catabolic hormones (cortisol, catecholamines, glucagon) and inhibition of insulin secretion and insulin resistance lead to amendment of energy conversion pathways [3]. Metabolic changes based on mobilizing internal sources of energy (glycogen, lipids, increased glycogenosis of endogenous substances, proteolysis) and hormonal changes take place in parallel, which increases their intensity [11].

The immunological state of critically ill patients is a dynamic process. The innate immune response, also defined as a non-specific response, is the first line of defense and its effector cells are neutrophils and monocytes/macrophages. The second line of defense is cellular ( $T$ cells) and humoral (B cells) acquired immune response [3]. Surgical stress, burns and injuries induce an inflammatory reaction with mainly intracellular mediators - the nuclear transcription factor $\kappa B(N F \kappa B)$ and nuclear activator protein (AP-1), which begin transcription of DNA and stimulate the synthesis of intercellular mediators: interleukins IL-1, IL-6, IL-8, IL-12, tumor necrosis factor $\alpha$ (TNF- $\alpha)$, and interferon $\gamma($ IFN- $\gamma)$. Simultaneous immune defense is due to cellular (lymphocytes, macrophages, neutrophils) and humoral activity (IL-4, IL-10, IL-11, IL-13, IL-15) [1, 12]. Proinflammatory cytokines aggravate metabolic effects, develop deficiency of micronutrients (copper, zinc, iron) and decrease the antioxidant defense system. Produced in the course of the inflammatory response, reactive oxygen species (ROS) increase the activation of nuclear transcription factors, cytokines, and adhesion molecules [3].

\section{Malnutrition}

In the state of long-term nutrient deficiency there occur indicators of deterioration of physical and mental health. Anxiety and depression are often associated with deficiencies of vitamins (thiamine, $\mathrm{B}_{12}$ ) and microelements (calcium, magnesium, phosphorus). Trophic changes of internal organs (heart, kidney, liver) with symptoms of their failure were also observed. Deficiency of protein greater than $20 \%$ due to a negative impact on the structure and function of the respiratory muscles and lung parenchyma leads to a reduction in weight and respiratory muscle strength, reduces neuronal respiratory drive, and causes abnormal ventilation, prolonged respiratory therapy and increased risk of infection. Malnutrition through a range of mechanisms leads to weakening of the immune defense of the body: it causes atrophy of lymph nodes, inhibits the maturation and differentiation of lymphocytes, reduces the secretion of IgA, and suppresses the cellular response [13]. Very important is the local effect of nutrition in the gastrointestinal tract and its impact on the body's defense mechanisms. It is known that the mucosa of the gastrointestinal tract tissue is $65 \%$ of the immune system tissue and its proper functioning depends on the presence of nutrients in the gut, which is the most potent stimulator of defense processes $[3,14]$. Otherwise the maintenance of normal immune function of the body plays an important role in maintaining the continuity and integrity of the gastrointestinal tract. Enteral nutritional therapy has a protective effect on the gastrointestinal tract: it maintains the continuity of intercellular communication, increases visceral blood flow, stimulates the secretion of trophic factors, and strengthens the protective effect of immunoglobulin A (IgA) in the lymphoid tissue gut-associated lymphoid tissue (GALT) and mucosal-associated lymphoid tissue (MALT) [4]. 
It has been proved that insufficient supply of energy leads to the activation of additional metabolic pathways and consumption of endogenous substances - proteins, lipids and carbohydrates - which eventually leads to weight loss. Loss of $10 \%$ of ideal body weight within 3-4 months leads to changes in function of the immune system. It is described that among patients with diagnosed cancer of the gastrointestinal tract $90 \%$ were malnourished [13, 15]. Energy requirement is estimated based on anthropometric data: age, sex, weight, height, and markers of the metabolic consumption of $\mathrm{O}_{2}$ and generation of $\mathrm{CO}_{2}$. The estimated daily energy requirements of hospitalized patients is $25-35 \mathrm{kcal} / \mathrm{kg}$, and hypercatabolic states such as surgery, trauma, burn or infection increase it up to $35-45 \mathrm{kcal} / \mathrm{kg}$ [4]. There were no significant benefits from the use of a higher-calorie diet. Overfeeding understood as providing nutrients in amounts greater than the demand did not accelerate the process of healing and weight gain; on the contrary, an excess of glucose in the blood resulted in protein glycosylation and limited phagocytic function of neutrophils. On the other hand, increased content of polyunsaturated fatty acids disturbed the function of the reticuloendothelial system. This leads to increased risk of infection and immune disorders. A group of symptoms characteristic for excessive supply of nutrients in the case of concomitant malnutrition has been described and called refeeding syndrome. Accumulation of fluids, dysregulation of vitamin metabolism and electrolyte imbalance (potassium, magnesium, phosphate) are the main symptoms of the syndrome. Severe complications seen in the course are pulmonary edema, loss of consciousness and respiratory failure leading to death $[3,16]$.

\section{The effect of particular nutrients on the body defense functions \\ Proteins and amino acids}

It has been proven that both quantitative and qualitative participation of proteins in a nutritional mixture is very important for the proper function of the immune system. It has been determined that the daily protein requirement for the healthy human is about $0.8 \mathrm{~g} / \mathrm{kg}$, which should be about $12 \%$ of the calorific value of the mixture. Patients in an intensive care unit require an increased supply of proteins, that is approximately 1.5 $2.0 \mathrm{~g} / \mathrm{kg} /$ day. In many publications the impact of certain amino acids on the immune system function was highlighted $[1,16]$.

Arginine accelerates transformation and maturation of $T$ cells, increases the activity of cytotoxic $T$ lymphocytes and $\mathrm{K}$ cells, and enhances the mitotic response of macrophages to inflammatory reactions [9]. Arginine metabolism is multidirectional. As a result of changes in the liver there are produced two important compounds: urea and ornithine. The urea is used in the synthesis of proline, which is also necessary for proper formation of collagen, the main component of connective tissue. Ornithine is a substrate for the synthesis of nucleotides and regulation of genetic transformation of cells. Arginine is also a source of nitric oxide, which regulates vascular connection, the adhesive properties of endothelial and inflammatory cells, the local activity of coagulation factors and immune modulating activity $[17,18]$.

Glutamine is an essential element supporting the natural intestinal barrier. It is a precursor for biosynthesis of nucleotides, and an energy substrate for rapidly dividing cells: macrophages, lymphocytes, endothelial cells, enterocytes [9]. The problem in the practical application of glutamine in parenteral nutrition is the instability of this compound in aqueous solution [19-21]. In experimental models other beneficial effects of other amino acids have been presented. Glycine showed a cytoprotective mechanism during experimental ischemia and reperfusion, while taurine has been reported to regulate apoptosis activity [2]. Sulfur amino acids (methionine, cysteine, procysteine) as donors of sulfhydryl groups and of glutathione synthesis stimulators exhibit antioxidant activity [1, 3]. Metabolic relationships between the main amino acids are shown in Figure 1.

\section{Lipids}

Lipids are components of cell membranes, a source of energy and the precursors of many mediators. The group of polyunsaturated fatty acids, which are $\omega-3$, $\omega-6, \omega-9$ fatty acids, is of particular importance. They are the most common constituents of cell membranes. It has been shown that dietary polyunsaturated fatty acid deficiency causes atrophy of the lymphatic tissue and disturbances of the humoral response [16]. Omega- 6 fatty acids are the precursors of arachidonic acid, which is the source for synthesis of proinflammatory mediators: IL-1, IL-6, TNF- $\alpha$. A reversed ratio of $\omega-6$ to $\omega-3$ fatty acids in favor of a higher content of $\omega-3$ reduces the pro-inflammatory effects through desaturase inhibition and prevents the conversion of compounds of $\omega-6$ to arachidonic acid. Omega- 3 fatty acids replace $\omega-6$ in the construction of the phospholipids of biological membranes, thereby enhancing the synthesis of anti-inflammatory prostaglandins and leukotrienes [1, 8, 9]. The greatest therapeutic expectations are connected with using $\omega-3$ fatty acids that are not synthesized in the body, and therefore their only source is an exogenous supply. These compounds exhibited the ability to selectively inhibit a signaling cascade associated with the first stage of non-specific resistance by undermining the 


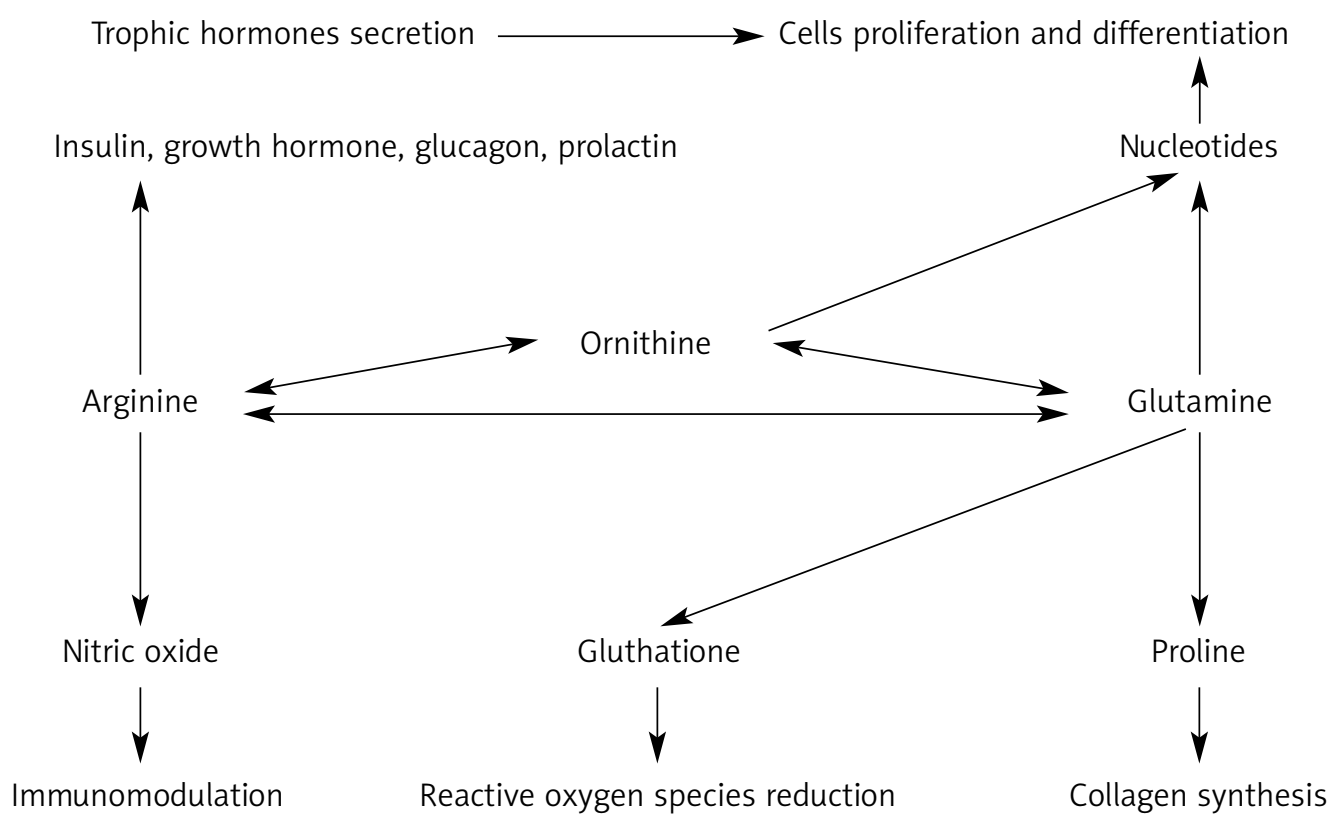

Fig. 1. Metabolic pathways among particular amino acids

Ryc. 1. Zależności metaboliczne pomiędzy poszczególnymi aminokwasami

impact of the endotoxin receptor Toll-like receptor (TLR), the activation of kinases that phosphorylate transcription factor $\mathrm{NF} \kappa \mathrm{B}$ inhibitor $\left(\mathrm{I}_{\mathrm{K}} \mathrm{B}\right)$ and translocation of this protein to the appropriate DNA sequence, which consequently resulted in inhibition of transcription of genes that encode mediators of the inflammatory response [22]. Omega-3 fatty acids show anti-inflammatory effects - they inhibit activity of mediators IL-1, IL-2, IL-4, IL-6, IL-8, IL-10, INF- $\gamma$, TNF, and platelet-activating factor (PAF), decrease the expression of adhesion molecules (selectins), reduce adhesion of inflammatory cells (lymphocytes, monocytes) to endothelial cells and neutrophil chemotaxis, and limit local production of nitric oxide and free oxygen radicals. These compounds have shown pro-mitotic activity, stimulating the differentiation of cells of the immune system [23, 24]. Changing the proportion of fatty acids in nutrients leads to change in the release of phospholipase products - prostaglandins and leukotrienes - which leads to modulation of immune system function [3].

\section{Vitamins, micro- and macroelements}

In the presence of metabolic stress there occur disturbances of vitamin metabolism. Through the excessive formation of reactive oxygen species, the increase of consumption of antioxidant vitamins, decrease in the amount of carrier proteins and acceleration of metabolism are seen. Water balance disturbances and concomitant renal replacement therapy also deepen problems with vitamins and their bioavailability in the body
[3]. It was found that $\beta$-carotene (vitamin A precursor) amplified the cytotoxic effects of macrophages, $T$ cells and NK cells, and accelerated mitotic activity of lymphocytes and their differentiation. Otherwise, vitamins $C$ and $\mathrm{E}$ exhibited antioxidant activity [1, 9, 12]. Experimental studies confirmed the beneficial immunomodulating effects of the microelements iron, manganese, magnesium, copper, selenium, chromium and zinc. Iron deficiency was the cause of impairment of cellular and humoral immune responses, and the state was predisposing to occurrence and development of infection [16]. Zinc deficiencies are associated with atrophy of lymphoid tissue. Increased demand for this trace element was observed among children and young people, older people and in such conditions as burns, skin lesions and fistula, where about $80 \%$ of the daily requirement for this element may be lost $[1,8,16]$. This microelement is necessary for the proper activity of the enzymes synthesizing nucleic acids and proteins. Zinc is also important in the regeneration of damaged tissues $[3,10]$. Copper, molybdenum and manganese are components of the antioxidant protection system (zinc copper cofactor of superoxide dismutase, sulfur oxidase, xanthine oxidase). Copper plays an important role in the normal function of neutrophils, and as a cofactor of lysine oxidase affects the structure of the connective tissue proteins collagen and elastin $[10,16]$.

Selenium is present in the body in the form of the amino acid selenocysteine, which is a component of many enzymes, including enzymes responsible for the 
synthesis of thyroid hormones, and glutathione peroxidase, responsible for the intracellular and extracellular oxidation-reduction system. Therefore, selenium impacts the function of the immune system, stimulates the activity of neutrophils, and increases the phagocytic activity of macrophages. Selenium also increases the expression of the receptor for IL-2, T cell proliferation, activation of $\mathrm{K}$ cells, NK cells and cytotoxic lymphocytes, increases antigen presentation by macrophages and dendritic cells, and activates B cells. Selenium affects both the inflammatory response and components of specific immunity: humoral and cellular [25].

Early clinical studies demonstrated the occurrence of oxidative stress associated with a significant decrease in the concentration of selenium and glutathione peroxidase activity in the course of acute pancreatitis, which correlated with the severity of the disease [26]. Similarly well documented is the reduction in serum selenium concentration in patients in the course of sepsis, trauma and burns. Many attempts have aimed at therapeutic supplementation of glutathione, selenium and administration of glutathione peroxidase analogues, such as ebselen, with various degrees of success. The largest of these trials proved that selenium supplementation with sodium selenide in high doses in patients with severe sepsis and septic shock was associated with a significant reduction in mortality (about 14.3\%) and was associated with increased plasma levels of glutathione peroxidase [27].

Nucleotides are the basic components of the genetic material - the nucleic acids DNA and RNA - and their deficiencies have been associated with the inhibition of cell-mediated immunity [2].

\section{American Society for Parenteral and Enteral Nutrition and Society of Critical Care Medicine guidelines for immunonutrition}

A particular challenge in terms of the choice of the route of administration of nutrients as well as proper selection of a nutritional mixture is posed by patients in intensive care units. This is due to the large heterogeneity of the patients, which include the elderly, patients with cancer, people with injuries as well as patients after major surgery, mechanically ventilated and often in shock. In a large group of ICU patients, in addition to acute circulatory or respiratory failure, the presence of infection is diagnosed. The most common infections in the ICU is pneumonia in general patients and intraabdominal infections in the population of surgical patients. Hence, it is a group of patients in which the function of the immune system is of particular importance, and its improvement may bring tangible benefits.
The latest guidelines published by American Society for Parenteral and Enteral Nutrition (A.S.P.E.N.) and Society of Critical Care Medicine (SCCM) contain the following recommendations concerning the method of nutrition and composition of the mixture [4].

1. Nutritional therapy in the form of enteral feeding should be started in critically ill patients, incapable of independent food intake within 24-48 h after cardiopulmonary stability. Enteral nutrition is preferred.

2. Nutritional therapy for patients undergoing extensive surgery, unable to self-feed and suffering from malnutrition, should include parenteral nutrition deployed for 5-7 days before surgery and continued in the postoperative period. Parenteral nutritional therapy lasting less than 5-7 days has no benefits and it is a risk to the patient. Therefore it should be implemented in a situation where the expected duration of therapy is longer than 7 days.

3. Nutritional formulas containing active substances affecting the activity of the immune system should only be used for appropriate groups of patients: patients after major surgery, burns, trauma, cancer of the head and neck, in critically ill patients requiring mechanical ventilation, with particular attention to patients with severe sepsis.

4. Patients suffering from other diseases should receive a standard formula for enteral nutrition.

5. Immunonutrition enriched with arginine may be used in mild to moderate sepsis; a severe stage should be subject to prudent assessment. The mechanism of the adverse action of arginine in sepsis is the essence of metabolism and transformation of the amino acid - an excess of nitric oxide promotes hemodynamic instability.

6. Patients with acute lung injury (ALI/ARDS (Definition missing.) requiring mechanical ventilation should receive enteral nutrition enriched with lipids $(\omega-3)$ and antioxidants with immunomodulating activity. The use of these components significantly reduces the length of ICU hospitalization and need for mechanical ventilation, and also reduces organ damage and mortality.

7. In order to obtain the benefits of immunonutrition the diet should contain $50-65 \%$ of total energy requirement.

8. Enrichment of nutrition with vitamins (C, E), antioxidants, and trace elements (selenium, zinc, copper) is indicated in patients with burns, trauma and requiring mechanical ventilation.

9. The administration of increased amounts of glutamine to enteral nutrition may be considered in the treatment of patients with burns and trauma. The recommended dose is $0.3-0.5 \mathrm{~g} / \mathrm{kg} /$ day in $2-3$ divid- 
ed doses. Enteral administration of glutamine showed no systemic antioxidant effects; its effect is limited to local protection and nutrition of intestinal epithelium.

10. Parenteral nutrition may also be enriched with glutamine to obtain systemic effects. The therapeutic problem is to obtain a suitable and chemically stable form of glutamine.

\section{Use of immunonutrition}

According to A.S.P.E.N. recommendations the use of nutrients with immunomodulatory properties is recommended; it is associated with obtaining therapeutic benefits in patients with injuries or burns, after extensive surgery due to cancer, and in patients requiring mechanical ventilation because of lung injury. Use in other clinical settings is controversial, and objective assessment of the effectiveness of therapy requires broadened clinical trials [4].

The most important recommendation in nutritional therapy in acute pancreatitis (AP) according to guidelines is the early implementation of enteral nutrition; in addition to covering energy needs it also provides immune protection resulting from the support of structural and functional integrity of the gastrointestinal tract. In mild and moderate acute pancreatitis enteral nutrition is recommended when oral food intake will not be possible for 7 days or longer. Enteral nutrition is the preferred route for nutritional support. It is recommended that nutritional therapy using mixtures supplied to the downstream sections of the gastrointestinal tract in the form of a continuous infusion, containing simple forms of lipids and peptides, be applied. These solutions limit the secretion of pancreatic enzymes [4]. Enteral feeding showed more favorable effects than parenteral. Decrease in mortality due to concomitant infections, shorter hospitalization, lower incidence of complications requiring surgical intervention and reduction in the incidence of organ failure has been reported [4, 28]. Implementation of parenteral nutrition should be considered in the course of severe acute pancreatitis [4]. Opinions about using mixtures enriched with immunomodulating compounds remain controversial [4, 14, 29, 30]. Ping et al. found that the implementation of an intravenous infusion of L-alanyl glutamine at the start of hospitalization significantly reduced the incidence of complications of acute pancreatitis compared to the start of this treatment after 5 days. The authors observed a reduced incidence of organ failure: respiratory, kidney, and liver. At the same time they found that early glutamine therapy reduced the risk of infection and complications requiring surgery, shortened hospital stay, contributed to the improvement of the general condition of the pa- tient, stabilized the vital signs assessed by APACHE II score in the 15-day period and decreased mortality [29]. Pearce et al., comparing the effect of enteral immunonutrition with standard nutritional therapy on the course of acute pancreatitis, found no advantages with immunotherapy according to biochemical and prognostic markers of inflammation in the course of the disease [30].

Another controversial aspect of immunonutrition is using it in sepsis. Bower et al., examining the impact of enteral immunonutrition compared with standard formula, observed a significant increase in mortality rate during immunotherapy (25\%) compared to the control group (8.9\%). Enteral immunonutrition also limited the development of infections and shortened hospitalization [31]. Similar effects were presented by Bertolini et al. [6]. The results of the immunomodulatory nutritional therapy in sepsis are ambiguous. Galban et al. estimated that the use of substances with immunological activity decreased mortality (19\%) compared with the control group (32\%). Beneficial effects of immunonutrition were more pronounced in patients assessed from 10 to 15 points in the APACHE II score than in patients with less severe organ dysfunction markers. The main problems of nutritional immunomodulatory therapy are due to effects associated with the administration of arginine and active metabolites of this amino acid [32]

In the course of sepsis there were described changes in protein metabolism, increased proteolysis and endogenous production of amino acids, including arginine being reduced to $1 / 3$. Many inflammatory mediators (IL-4, IL-10) increased catabolism of arginine by enhancing activity of arginase I, while others (IL-1, IL-2, TNF- $\alpha$, INF- $\gamma$ ) elicited increased activity of inducible nitric oxide synthase. The biological effect of nitric oxide leads to hypotension and deterioration of circulatory efficiency [33]. Exogenous arginine supplementation in sepsis is a controversial subject. Luiking and Deutz while publishing an analysis showed examples of studies in which the intravenous amino acid therapy resulted in direct but transient hemodynamic changes resulting from vasodilatation in the systemic and pulmonary circulation [34].

During continuous intravenous infusion of arginine there were no changes in circulatory parameters [33, 34]. Many factors affecting the bioavailability of arginine in the nutritional immunotherapy were described. Enteral administration of arginine was associated with reduced biological availability due to the presence of the first pass effect, which accounted for about $40 \%$, and due to reduced absorption of the amino acid in the intestine in sepsis. Bioavailability of arginine given enterally accounted for approximately $20 \%$, which was significantly 
lower than when given in the intravenous form (about $60 \%)[33,34]$.

According to the A.S.P.E.N. recommendations there is no proven evidence of a beneficial effect of immunonutrition in sepsis, and before starting it the benefits and risks of therapy should be considered [4]. Strict indications for conducting nutrition enriched with nutrients with immunomodulating activity are the pre- and postoperative periods, particularly in patients with diagnosed cancer. Preoperative nutritional deficiency increases the incidence of systemic (about 50\%) and local complications (20-30\%) in the postoperative period [35]. It has been reported that immunonutrition therapy reduces the risk of local and systemic infectious complications, and reduces time of hospitalization and artificial ventilation and overall mortality [31, 33, 36-39]. Assessment of the impact of such nutritional therapy for differentiation of immune cells revealed reduced incidence of complications, which was associated with increased differentiation, maturation and restoration of particular lymphocyte subsets: Th1, Th2, Th17 [36]. Sorensen and colleagues have studied the effects of perioperative nutritional immunotherapy in the course of head and neck cancer and reported favorable changes: inhibition of immunosuppression, the count of lymphocyte subpopulations, markers of inflammation and nutritional status - concentrations of C-reactive protein, albumin, prealbumin and postoperative course [13, 35]. Słotwiński et al. found that enteral nutrition mixtures enriched with immunoactive components limited severity of traumatic stress, stimulated anti-inflammatory cytokine synthesis and by affecting interleukin-1 receptor antagonist (IL-1RA) reduced the biological activity of IL-1. The authors showed that, among all studied biological mediators, IL-1RA was the most sensitive marker of anti-inflammatory activity. As a result of nutritional therapy the authors observed a temporary increase in the concentration of this substance, associated with the accelerated process of systemic recovery and proper local wound healing and tissue regeneration [15].

\section{Future of immunonutrition}

It has been reported that some of the immunonutrients affect gene expression, transcription and transformation of the genetic material - the effect is defined as nutrigenomics. The subject of experimental research is the effective reduction of the excessive inflammatory response (decrease in $\mathrm{NF \kappa B}$ activation, production of proinflammatory cytokines, chemokines, adhesion molecules, regulation of differentiation and apoptosis of neutrophils and lymphocytes) by using a well-balanced nutritional therapy $[3,22]$. Glutamine, $\omega-3$ fatty acids, vitamin $D$, selenium, zinc, and nutrients such as fiber- containing long chain fatty acids exhibited indirect activity regulating gene expression through its influence on the second messengers and mediators. In view of the many publications, some nutrients may be relevant and applicable in the treatment of diseases with a genetic background in terms of genetic material repair, cell differentiation and apoptosis [17, 20].

The scope of experimental studies in animal models still includes the modulation of protein expression and cell-signaling pathways involved in the innate immune response (neutrophils, monocytes, macrophages) by nutritional therapy. It has been reported that the shortage of immunologically active nutrients ( $\omega-3$, glutamine) resulted in decreased expression of the receptors (TLR-4 - Toll-like receptor), adapter proteins and extra- and intracellular enzymes (MyD 88 - myeloid differentiation factor 88, TRAF6 - TNF- $\alpha$ receptor-associated factor 6) which potentiate the synthesis of pro-inflammatory cytokines [22].

Pharmaceutical companies offer diets for enteral nutrition enriched with nutrients of immunomodulatory activity: Supportan, Reconvan, Glutamine Plus, Intestamin, Nutrison Advanced Cubison, Nutrison Advanced Protison, Forticare. Parenteral nutrition therapy in the form of commercially prepared mixtures is not available in Poland. Targeted nutritional therapy should include all groups of nutritients with immunological action. Dipeptiven is the special immunomodulating parenteral formula consisting of two aminoacids: glutamine and alanine. Lipids formula enriched with omega-3 polyunsaturated fatty acids are Omegaven and Lipoplus. Vitamins and microelements of immunomodulating properties can be found in most commercially available mixtures: Soluvit, Addamel, Cernevit, Tracutil, Decaven and Vitalipid [40-43].

Immunonutrition is undeniably one of the most important components of intensive care. At the same time it remains a point of interest to other fields of medicine - internal medicine, surgery and oncology. The primary objective is to modulate the immune response by the supply of naturally occurring nutrients in order to reduce tissue damage in the course of the inflammatory response, reducing the risk of infection and mortality and improving the survival rate. It is an important part of the treatment recommended by A.S.P.E.N. and SCCM $[2,4,8]$. In order to benefit from the immunotherapy, proper selection of patients is essential. The highest efficiency was reported in trauma and surgical patients. In the intensive care unit reducing the risk of infectious complications and shortening the time of mechanical ventilation and hospitalization were effective both in adults and children, before and after surgery [4, 8, 21, $44,45]$. Despite the ambiguous results of trials lasting 
for more than a quarter of a century, immunonutrition still remains an open topic. The major limitation of these trials is the low number of patients in studied groups, their heterogeneity and different research protocols. In practice, any further study will generate new questions rather than answer persistent doubts [46]. However, our knowledge of the pathophysiology of the inflammatory response and the immune system is constantly increasing, along with the rapidly increasing knowledge of specific dietary ingredients. Currently, a large randomized controlled trial (1200 patients), a multicenter study on the efficacy of co-administration of glutamine and antioxidants in preventing death in patients in the intensive care unit - REDOXS (Reducing Deaths due to Oxidative Stress) - is being performed [47]. Perhaps the results of such research will permit the rationalization of nutritional support and help us make the right choices in clinical practice.

\section{References}

1. Grimble RF. Immunonutrition. Curr Opin Gastroenterol 2005; 21: 216-22.

2. Standen J, Bilhari D. Immunonutrition: an update. Curr Opin Clin Nutr Metab Care 2000; 3: 149-57.

3. Sobotka L. Basics in clinical nutrition. 3rd ed. [Polish]. Korta T (ed.). PZWL, Warsaw 2007.

4. McClave SA, Martindale RG, Vanek VW, et al. Guidelines for the provision and assessment of nutrition support therapy in the adult critically ill patient: Society of Critical Care Medicine ( SCCM) and American Society for Parenteral and Enteral Nutrition (A.S.P.E.N.). JPEN J Parenter Enteral Nutri 2009; 37: 277-316.

5. Norbury WB, Situ E, Herndon DN. Nutritional support in critically ill. In: Current surgical therapy. Cameron JL (ed.). Philadelphia, Mosby 2008; 1234-44.

6. Bertolini G, Luciani D, Biolo G. Immunonutrition in septic patients: a philosophical view of the current situation. Clin Nutr 2007; 26: 25-9.

7. Scrimshaw NS. Immunonutrition in health and disease. Prologue: historical Introduction. Br J Nutr 2007; 98 suppl. 1: S3-4.

8. Dupertuis YM, Meguid MM, Pichard C. Advancing from immunonutrition to pharmaconutrition: a gigantic challenge. Curr Opin Clin Nutr Metab Care 2009; 12: 398-403.

9. Tepaske R. Immunonutrition. Curr Opin Anaesthesiol 1997; 10: 86-91.

10. Strachan S. Trace elements. Curr Anaesth Crit Care 2010; 21: 44-8.

11. Reid CL, Campbell IT. Nutritional and metabolic support in trauma, sepsis and critical illness. Curr Anaesth Crit Care 2004; 15: 336-49.

12. Lin E, Kotani JG, Lowry SF. Nutritional modulation of immunity and the inflamatory response. Nutrition 1998; 14: 545-50.

13. Gunerhan Y, Koksal N, Sahin UY, et al. Effect of preoperative immunonutrition and other nutrition models on cellular immune parameters. World J Gastroenterol 2009; 15: 467-72.

14. Petrov MS, Atduev VA, Zagainov VE. Advanced enteral therapy in acute pancreatitis: is there a room for immunonutrition? A meta-analysis. Int J Surg 2008; 6: 119-24.
15. Slotwiński R, Olszewski WL, Slotkowski M, et al. Can the interleukin-1 receptor antagonist (IL-1ra) be a marker of antiinflammatory response to enteral immunonutrition in malnourished patients after pancreaticoduodenectomy? JOP 2007; 8: 759-69.

16. Krenitsky J. Nutrition and the immune system. AACN Clinical Issues 1996; 7: 359-69.

17. Evoy D, Lieberman D, Fahey T, et al. Immunonutrition: the role of arginine. Nutrition 1998; 14: 611-7.

18. Bansal V, Ochoa JB. Arginine availability, arginase, and the immune response. Curr Opin Clin Nutr Metab Care 2003; 6: 223-8.

19. Bistrian BR, McCowen KC. Nutritional and metabolic support in the adult intensive care unit: key controversies. Crit Care Med 2006; 34: 1525-31.

20. Zanello M, Di Mauro L, Vincenzi M. Therapeutic effects of artificial nutrition in intensive care patients: new insights. Curr Anaesth Crit Care 2006; 17: 375-83.

21. Kreymann KG. Early nutrition suport in critical: a European perspective. Curr Opin Clin Nutr Metab Care 2008; 11: 156-9.

22. Słotwiński R, Słotwińska SM, Kędziora $S$, et al. Alterations in innate antibacterial response after immunomodulating nutrition. Prz Gastroenterol 2009; 4: 231-7.

23. Wesley JA. Immunonutrition: the role of omega3 fatty acids. Nutrition 1998; 14: 627-33.

24. Mayer K, Schaefer MB, Seeger W. Fish oil in the critically ill: from experimental to clinical data. Curr Opin Clin Nutr Metab Care 2006; 9: 140-8.

25. Manzanares W, Hardy G. Selenium supplementation in the critically ill: posology and pharmacokinetics. Curr Opin Clin Nutr Metab Care 2009; 12: 273-80.

26. Wereszczyńska-Siemiatkowska U, Mroczko B, Siemiątkowski A, et al. The importance of interleukin 18 , glutathione peroxidase, and selenium concentration changes in acute pancreatitis. Dig Dis Sci 2004; 49: 642-50.

27. Angstwurm MW, Engelmann L, Zimmermann T, et al. Selenium in Intensive Care (SIC): results of a prospective randomized, placebo-controlled, multiple-center study in patients with severe systemic inflammatory response syndrome, sepsis, and septic shock. Crit Care Med 2007; 35: 118-26.

28. Eckerwall GE, Axelsson JB, Andersson RG. Early nasogastric feeding in predicted severe acute pancreatitis. A clinical, randomized study. Ann Surg 2006; 244: 959-67.

29. Ping X, Li-Hui D, Qing X, et al. Impact of alany-glutamine dipeptide on severe acute pancreatitis in early stage. World J Gastroenterol 2008; 14: 474-8.

30. Pearce CB, Sadek SA, Walters AM, et al. A double- blind, randomized, controlled trial to study the effects of an enteral feed supplemented with glutamine, arginine and omega- 3 fatty acid in predicted acute severe pancreatitis. JOP 2006; 7: 361-71.

31. Bower RH, Cerra FB, Bershadsky B, et al. Early enteral administration of a formula (Impact Registered Trademark) supplemented with arginine, nucleotides and fish oil in intensive care unit patients: results of a multicenter, prospective, randomized, clinical trial. Crit Care Med 1995; 23: 436-49.

32. Galban C, Montejo JC, Mesejo A, et al. An immune-enhancing enteral diet reduces mortality rate and episodes of bacteremia in septic intensive care unit patients. Crit Care Med 2000; 23: 643-8. 
33. Stechmiller JK, Childress B, Porter T. Arginine immunonutrition in critically ill patients: a clinical dilemma. Am J Crit Care 2004; 13: $17-23$.

34. Luiking YC, Deutz NP. Exogenous arginine in sepsis. Crit Care Med 2007; 35: S557-63.

35. Sorensen D, McCarthy M, Baumgartner B, et al. Perioperative immunonutrition in head and neck cancer. Laryngoscope 2009; 119: $1358-64$

36. Suzuki D, Furukawa K, Kimura F, et al. Effects of peri-operative immunonutrition on cell-mediated immunity, $\mathrm{T}$ helper type 1(Th1)/Th2 differentiation and Th17 response after panceaticoduodenectomy. Surgery 2010; 148: 573-81.

37. Heyland DK, Novak F, Drover J, et al. Should immunonutrition become routine in critically ill patients? A systematic review of the evidence. JAMA 2001; 286: 944-53.

38. Beale RJ, Bryg DJ, Bihari DJ. Immunonutrition in the critically ill: a systematic review of clinical outcome. Crit Care Med 1999; 27: 2799-805.

39. McCowen KC, Bistrian BR. Immunonutrition: problematic or problem solving? Am J Clin Nutr 2003; 77: 764-70.

40. Available at: www.fresenius.com.pl

41. Available at: www.chifa.com.pl

42. Available at: www.baxter.com.pl

43. Available at: www.nutricia.com.pl

44. Opilla M. Epidemiology of bloodstream infection associated with parenteral nutrition. Am J Infect Control 2008; 36: S173.e5-8.

45. Briassoulis G, Filippou O, Hatzi E, et al. Early enteral administration of immunonutrition in critically ill children: results of a blinded randomized controlled clinical trial. Nutrition 2005; 21: 799-807.

46. Jones NE, Heyland DK. Pharmaconutrition: a new emerging paradigm. Curr Opin Gastroenterol 2008; 24: 215-22.

47. Available at: www.criticalcarenutrition.com 